\title{
APLICAÇÃO DE DANOS MECÂNICOS EM ABACATES E SEUS EFEITOS NA QUALIDADE DOS FRUTOS
}

\section{JULIANA SANCHES ${ }^{1}$, JOSÉ F. DURIGAN ${ }^{2}$, MARIA F. B. DURIGAN ${ }^{3}$}

RESUMO: Este trabalho teve por objetivo avaliar o efeito da aplicação de danos mecânicos por impacto, compressão e corte em abacates 'Geada'. O trabalho consistiu em duas etapas: na primeira, o impacto foi aplicado deixando-se os frutos caírem, em queda livre, de $1,5 \mathrm{~m} \mathrm{a} \mathrm{3,0} \mathrm{m,}$ com intervalo de $0,5 \mathrm{~m}$; na compressão, os frutos sofreram a ação dos pesos: $6 \mathrm{~kg}$ por 12 horas e $12 \mathrm{~kg}$ por 6 horas. Para os cortes, foram realizados quatro cortes com $80 \mathrm{~mm}$ de comprimento e $4 \mathrm{~mm}$ de profundidade. Na segunda etapa, para a compressão, utilizou-se peso de $12 \mathrm{~kg}$ por tempo maior (24 h). No impacto, foi aplicada queda de 2,0 m, e os cortes, realizados da mesma maneira que na primeira etapa. Os efeitos de cada dano foram avaliados nos frutos armazenados sob condição ambiente quanto à coloração, perda de massa fresca e teores de sólidos solúveis e de acidez titulável. Queda de alturas maiores que 2,0 m levaram os frutos a rachaduras. Até 2,0 $\mathrm{m}$ de altura, formaram-se fissuras ao redor do caroço, que foram preenchidas por filamentos de aspecto duro e não se tornou visível externamente. $\mathrm{O}$ abacate não se mostrou suscetível à aplicação das compressões $6 \mathrm{~kg} / 12 \mathrm{~h} \mathrm{e} 12 \mathrm{~kg} / 6 \mathrm{~h}$, mas o tratamento $12 \mathrm{~kg} / 24 \mathrm{~h}$ fez com que a casca apresentasse coloração verde mais escura durante três dias. Os cortes provocaram cicatrizes na casca.

PALAVRAS-CHAVE: compressão, corte, impacto, Persea americana.

\section{APPLICATION OF MECHANICAL DAMAGES IN AVOCADOS AND THEIR EFFECTS TO THE QUALITY OF THE FRUITS}

\begin{abstract}
The objective of this work was to evaluate the effect of mechanical damages application in 'Geada' avocado fruit by impact, compression, and cut. This work was carried out in two stages: first, the impact test was applied by free fall of the fruits, from $1.5 \mathrm{~m}$ to $3.0 \mathrm{~m}$, with steps of $0.5 \mathrm{~m}$. For the compression tests, fruits were loaded using blocks of two different weights: $6 \mathrm{~kg}$ for $12 \mathrm{~h}$ and $12 \mathrm{~kg}$ for $6 \mathrm{~h}$. Four cuts of $80 \mathrm{~mm}$, in length and $4 \mathrm{~mm}$, in depth were performed for the cut tests; second, for the compression tests was used blocks of $12 \mathrm{~kg}$ for longer time than the first one $(24 \mathrm{~h})$. In the impact test it was applied a $2.0 \mathrm{~m}$ free fall and cuts was carried out in the same way of first stage. The fruits were stored at room condition and evaluated for coloration, weight loss, total soluble solids and titratable acidity. The results showed that fall higher than $2.0 \mathrm{~m}$ promoted fissures in the fruits; up to $2.0 \mathrm{~m}$ high it was observed fissures in pit surrounding that was filled by filaments of rigid appearance that was not visible on the skin surface. The avocado fruit was not susceptible at compression application $(6 \mathrm{~kg} / 12 \mathrm{~h}$ and $12 \mathrm{~kg} / 6 \mathrm{~h})$, but at $12 \mathrm{~kg} / 24 \mathrm{~h}$ the skin exhibited darker green color than control fruits for three days. The cuts promoted skin scars.
\end{abstract}

KEYWORDS: compression, cut, impact, Persea americana.

\footnotetext{
${ }^{1}$ Eng $^{\mathrm{a}}$ Agr ${ }^{\mathrm{a}}$, Dra., Pesquisadora Científica, Instituto Agronômico, Centro de Engenharia e Automação. Tecnologia de Pós-Colheita. Rod. D. Gabriel P. B. Couto, km 65, Caixa Postal 26, Jundiaí - SP Fone: (0XX11) 4582-8155, jsanches@iac.sp.gov.br

2 Prof. Titular, Departamento de Tecnologia, Faculdade de Ciências Agrárias e Veterinárias, UNESP, Câmpus de Jaboticabal, Jaboticabal - SP.

${ }^{3}$ Eng $^{\mathrm{a}}$ Agr $^{\mathrm{a}}$, Mestre, Departamento de Tecnologia, Faculdade de Ciências Agrárias e Veterinárias, UNESP, Câmpus de Jaboticabal, Jaboticabal - SP.

Recebido pelo Conselho Editorial em: 15-12-2006

Aprovado pelo Conselho Editorial em: 25-2-2008
} 


\section{INTRODUÇÃO}

Os danos mecânicos são definidos como deformações plásticas, rupturas superficiais e destruição dos tecidos vegetais provocados por forças externas. Adicionalmente, levam a modificações físicas (danos físicos) e/ou alterações fisiológicas, químicas e bioquímicas que modificam a cor, o aroma, o sabor e a textura dos vegetais (MOHSENIN, 1986). Dentre os danos mais comuns, destacam-se os causados por impacto, compressão e corte.

O dano por impacto é geralmente causado pela colisão do fruto contra superfícies sólidas durante as etapas de colheita, de manuseio e de transporte, podendo causar danos externos que são facilmente visualizados na superfície, com a ruptura ou não da epiderme, ocasionando a formação de lesões aquosas translúcidas e amolecimento. Além disso, esses danos podem provocar a retirada da primeira linha de defesa do fruto colhido, permitindo a entrada de patógenos. A ocorrência de impactos pode não causar sintomatologia externa prontamente observável, mas seu efeito acaba repercutindo mais tarde, dada a produção de danos internos (QUINTANA \& PAULL, 1993; MORETTI, 1998).

O dano mecânico por compressão pode ser causado pela aplicação de pressão variável contra a superfície externa do fruto.

O dano por corte é geralmente atribuído a uma forte colisão do fruto contra uma superfície irregular, ou pela imposição de uma superfície cortante e com pressão sobre o fruto, como as arestas de embalagem de colheita ou objetos cortantes utilizados no processamento dos mesmos. Independentemente do caso, o resultado deverá ser o rompimento e a perda da integridade celular na região do corte (MOHSENIN, 1986; WILEY, 1997).

Segundo BLEINROTH \& CASTRO (1992), em abacate, não ocorre o efeito imediato de danos externos e somente quando a fruta está madura, a polpa se apresentará, parcial ou totalmente, escura.

Este trabalho teve por objetivo avaliar o efeito da aplicação de danos por impacto, compressão e corte em abacates e verificar seus efeitos sobre a qualidade dos mesmos.

\section{MATERIAL E MÉTODOS}

Adaptou-se a metodologia desenvolvida por MATTIUZ (2002), para goiabas, na qual, no dano mecânicos por impacto, as goiabas foram deixadas cair, em queda livre, de $1,20 \mathrm{~m}$ de altura. Para o dano correspondente à compressão, os frutos foram colocados sob um aparelho onde um bloco exercendo um peso de $3 \mathrm{~kg}$ era apoiado, por $15 \mathrm{~min}$. No dano por corte, foram realizados dois cortes de $30 \mathrm{~mm}$ de comprimento por $2 \mathrm{~mm}$ de profundidade, no sentido longitudinal dos frutos.

Para a realização deste trabalho, optou-se pela utilização de abacates da cultivar 'Geada', por ser a cultivar mais comercializada na CEAGESP (FRANCISCO \& BAPTISTELLA, 2005), representando 39\% do total de abacate comercializado em 2002 (CAMARGO \& MANCO, 2004). A cultivar 'Geada' apresenta colheita precoce (janeiro e fevereiro), alta percentagem de polpa (68\% ou mais) e baixa percentagem de óleo (menos de 9\%). É do tipo floral B, e o formato dos frutos é piriforme e elíptica, com peso variando de $500 \mathrm{~g}$ a $700 \mathrm{~g}$ (DONADIO, 1995, GAYET et al., 1995).

Os frutos foram cuidadosamente colhidos, com coloração verde-opaca, e facilidade de destacamento da planta (BLEINROTH, 1995), em propriedade agrícola no município de Jardinópolis - SP, sendo imediatamente transportados para o Laboratório de Tecnologia dos Produtos Agrícolas da FCAV/UNESP-Jaboticabal, onde foram recebidos íntegros. Isso foi conseguido tendo-se o cuidado de transportá-los por cerca de $60 \mathrm{~km}$, acondicionando-os em caixas plásticas, com duas camadas de frutos, forradas internamente, e entre as camadas com plásticobolha de $3 \mathrm{~mm}$ de espessura e papel-jornal.

Ao serem recebidos no laboratório, entre 1 e 2 horas após a colheita, os frutos foram novamente selecionados para tornar o lote ainda mais homogêneo quanto ao estádio de maturação, 
de coloração, de tamanho e ausência de danos mecânicos. Foram lavados com detergente neutro e enxaguados com água corrente para a eliminação de impurezas, antes de serem imersos em água fria $\left(5^{\circ} \mathrm{C}\right)$ e clorada $\left(150 \mathrm{mg}\right.$ de cloro $\left.\mathrm{L}^{-1}\right)$ por cinco minutos, para resfriamento. Esses frutos foram deixados em repouso por 1 hora $\left(25 \pm 1{ }^{\circ} \mathrm{C}\right.$ e $64 \pm 6 \%$ UR) antes de serem danificados mecanicamente.

\section{Etapa 1}

Em 20 de dezembro de 2002, os frutos foram divididos em lotes homogêneos, que sofreram os seguintes danos mecânicos:

Para o impacto, foram utilizadas as alturas de queda livre de $1,50 \mathrm{~m} ; 2,00 \mathrm{~m} ; 2,50 \mathrm{~m}$ e 3,00 m, e cada fruto recebeu dois impactos, em lados opostos de sua região equatorial. Para a realização do tratamento de compressão, utilizou-se do dispositivo conforme o esquema mostrado na Figura 1a, onde cada fruto sofreu a ação de peso conhecido de $6 \mathrm{~kg}(58,8 \mathrm{~N})$, por 12 horas, e $12 \mathrm{~kg}(117,6 \mathrm{~N})$, por 6 horas. As áreas danificadas pelo impacto e compressão foram evidenciadas usando-se partes iguais de glucose de milho e tinta guache, o que permitiu demarcá-las com caneta de retroprojetor, antes da lavagem com água (MATTIUZ, 2002). O dano por corte constou de quatro cortes, com $4 \mathrm{~mm}$ de profundidade e $80 \mathrm{~mm}$ de comprimento, em cada lado do fruto, no sentido longitudinal, usando-se faca modificada (Figura 1b), com lâmina de 1,1 mm de espessura.

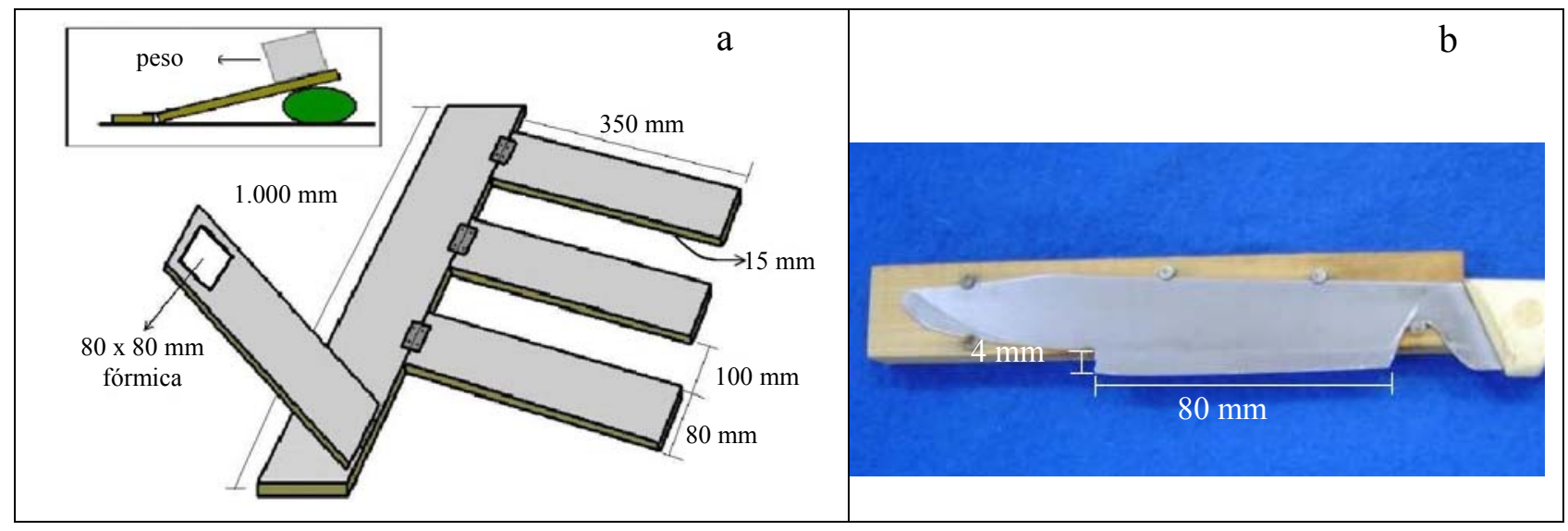

FIGURA 1. (a) Esquema do aparelho para provocar dano por compressão; (b) Faca modificada para provocar dano por corte. (a) Layout of the equipment to promote compression damage; (b) Modified knife to promote cut damage.

Os frutos dos lotes submetidos aos diferentes danos mecânicos tinham as porções danificadas localizadas nos lados opostos de sua linha equatorial, e a porção, aparentemente intacta, na vizinhança. Os frutos da testemunha, sem dano, também tiveram regiões equivalentes às áreas danificadas na linha equatorial e nas laterais marcadas, para que os resultados pudessem ser comparados.

Os lotes de frutos danificados e a testemunha foram armazenados em sala com condições controladas de ambiente $\left(25 \pm 1^{\circ} \mathrm{C}\right.$ e $64 \pm 6 \%$ UR), até que eles se tornassem impróprios para a comercialização. Durante o período de armazenamento, aos 1; 3; 6 e 8 dias, avaliaram-se a coloração da casca, a massa fresca e os teores de sólidos solúveis e de acidez titulável.

Dentro de cada lote, um grupo contendo três frutos submetidos ao tratamento foi utilizado para a determinação da massa fresca e da coloração, o que permitiu avaliar a evolução desses parâmetros ao longo do período de armazenamento, utilizando-se sempre dos mesmos frutos. A coloração da casca foi sempre determinada em regiões danificadas e não-danificadas, e previamente marcadas para que as leituras fossem feitas sempre nos mesmos locais.

Os frutos foram submetidos às seguintes análises: 
- Massa fresca: foi determinada utilizando-se de pesagem em balança digital com capacidade para $2 \mathrm{~kg}$ e precisão de $0,1 \mathrm{~g}$;

- Coloração externa: as análises foram feitas utilizando-se de reflectômetro MINOLTA Chroma Meter CR-200b, que expressa esse parâmetro, segundo o sistema proposto pela Comission Internacionale de l'Eclaraige - (CIE) em L*a*b*. O diâmetro da área de leitura do colorímetro é de $1,2 \mathrm{~cm}$. As determinações foram realizadas nas quatro regiões previamente marcadas nos frutos, ou seja, duas na região danificada e duas na região não-danificada. A coloração foi expressa pela luminosidade, pela cromaticidade e pelo ângulo de cor (Hue), conforme metodologia descrita por WOOLF et al. (1997);

- Acidez titulável: foi determinada em $10 \mathrm{~g}$ de polpa homogeneizada com $50 \mathrm{~mL}$ de água destilada, por meio de titulação com $\mathrm{NaOH}$ a $0,01 \mathrm{~N}$, padronizada e expressa em gramas de ácido cítrico por 100 gramas de amostra (AOAC, 1997 - método 942.15);

- Sólidos solúveis: utilizou-se de refratômetro digital (Atago Palette, mod. PR-101), expressando os resultados em ${ }^{\circ}$ Brix (AOAC, 1997 - método 932.12).

A condução dessa etapa seguiu delineamento experimental inteiramente casualizado, em esquema fatorial $4 \times 12$, em que os fatores foram as épocas de análise (4) e tendo-se como tratamentos: testemunha; compressão (12 kg/6 h); compressão (6 kg/12 h); corte; impacto da altura de $2,0 \mathrm{~m}$ e impacto de $1,5 \mathrm{~m}$, divididos em partes danificadas e não-danificadas. Todas as análises foram realizadas em triplicata.

As evoluções das perdas de massa fresca pelos frutos submetidos aos diferentes tratamentos foram comparadas por meio do paralelismo das retas, Teste $t$, conforme o proposto por NETER et al. (1978), e os teores de sólidos solúveis, de acidez titulável e de coloração, por meio de teste de Tukey.

\section{Etapa 2}

Essa etapa, que se iniciou no dia 10 de janeiro de 2003, também foi realizada com frutos da cultivar 'Geada' para testar maiores períodos de exposição ao peso, no tratamento compressão, pois, na primeira etapa, os frutos não se mostraram suscetíveis a esse dano.

O experimento foi realizado de maneira semelhante ao realizado na primeira etapa, na qual, no impacto, os frutos foram deixados cair, em queda livre, de 2,00 m de altura; na compressão, foram colocados sob a ação de um bloco para pressão de $12 \mathrm{~kg}(117,6 \mathrm{~N})$ por $24 \mathrm{~h}$; os cortes foram também realizados em número de quatro, nos lados opostos e no sentido longitudinal dos frutos, com $4 \mathrm{~mm}$ de profundidade e $80 \mathrm{~mm}$ de comprimento, com lâmina de $1,1 \mathrm{~mm}$ de espessura, e na testemunha, os frutos não sofreram qualquer dano.

Semelhantemente à primeira etapa, cada um dos frutos submetidos aos tratamentos apresentou as porções danificadas localizadas nos lados opostos de sua linha equatorial e a porção aparentemente intacta, nas vizinhanças.

Após esses tratamentos, os frutos foram armazenados em sala com condições controladas de ambiente $\left(25 \pm 1^{\circ} \mathrm{C}, 62 \pm 6 \%\right.$ UR), até que se tornassem impróprios para comercialização. Durante o período de armazenamento, aos 1; 3; 6 e 8 dias, eles também foram avaliados quanto à coloração da casca, massa fresca, e teores de sólidos solúveis e de acidez titulável. Todas as análises foram realizadas em triplicata.

Nessa etapa, o trabalho também obedeceu ao delineamento experimental inteiramente casualizado, em esquema fatorial 4 × 8, em que foram consideradas as quatro épocas de análise e os tratamentos-testemunha, compressão, corte e impacto, em suas partes injuriadas e não-injuriadas. Os resultados referentes à evolução de perda de massa fresca e aos teores de sólidos solúveis, acidez titulável e coloração foram estatisticamente avaliados de forma semelhante à primeira etapa. 


\section{RESULTADOS E DISCUSSÃO}

\section{Etapa 1}

Os abacates 'Geada' danificados por corte apresentaram marcas que puderam ser observadas desde o primeiro dia e evoluíram de leves sinais para tecidos lignificados, estabelecendo-se, progressivamente, uma cicatriz em oito dias de armazenamento. Vale ressaltar que, no oitavo dia de armazenamento, quando os frutos estavam amadurecidos, a casca era retirada com facilidade, assim como as cicatrizes formadas pelos cortes.

O impacto resultante das quedas de $2,5 \mathrm{~m} \mathrm{e} \mathrm{3,0} \mathrm{m}$ de altura provocou rachaduras nos frutos, conforme visualizado na Figura 2, o que não ocorreu para as alturas de 2,0 m e 1,5 m. Embora os abacates não apresentassem sintomas externos visíveis após a queda de $2,0 \mathrm{~m}$ e $1,5 \mathrm{~m}$, a polpa, ao redor do caroço, apresentou fissuras após três dias. À medida que os frutos foram amadurecendo, as fissuras foram sendo preenchidas por filamentos do caroço, fazendo com que as mesmas não evoluíssem até a casca.

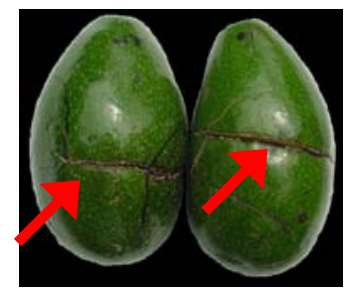

$3,0 \mathrm{~m}$

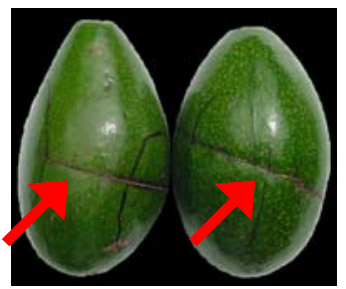

$2,5 \mathrm{~m}$

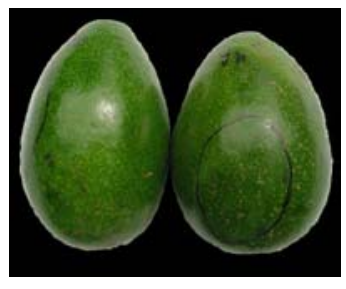

$2,0 \mathrm{~m}$

FIGURA 2. Abacates 'Geada' submetidos ao impacto de 3,0 m, 2,5 m e 2,0 m de altura. 'Geada' avocados submitted to impact at $3.0 \mathrm{~m}, 2.5 \mathrm{~m}$, and $2.0 \mathrm{~m}$ high.

Observando-se a evolução da luminosidade nas áreas danificadas e nas não-danificadas, ao longo do período de armazenamento (Figura 3), constatou-se que, nos frutos submetidos à compressão $(12 \mathrm{~kg} / 6 \mathrm{~h} \mathrm{e} 6 \mathrm{~kg} / 12 \mathrm{~h}$ ), as partes danificadas tenderam a maior escurecimento no primeiro dia de armazenamento, cuja intensidade da parte danificada também foi maior nos frutos submetidos ao maior peso.

Depois de três dias, esse escurecimento na casca não se mostrava mais visível. Os frutos de todos os tratamentos apresentaram aumento gradual na luminosidade, devido ao amadurecimento, e, no oitavo dia, todos os tratamentos apresentavam-se com coloração mais clara, típica de abacates amadurecidos.

Na Figura 3, também é mostrada a evolução dos valores do ângulo de cor nos abacates, permitindo observar que a cor não foi afetada pelos tratamentos aplicados e que, durante o período de armazenamento, se manteve sem modificação significativa até o oitavo dia, apesar de se observar diminuição no ângulo Hue, ao longo do período de armazenamento. Os frutos tornaram-se verde mais claro, com exceção da parte danificada pelo impacto causado pela queda de $2,0 \mathrm{~m}$, que se tornou verde mais escuro.

Observa-se que a cromaticidade da casca dos frutos não foi influenciada pelos danos mecânicos aplicados (Figura 3), com exceção da parte danificada do tratamento compressão $(12 \mathrm{~kg} / 6 \mathrm{~h})$, a qual apresentou a menor cromaticidade ao longo desse período. 

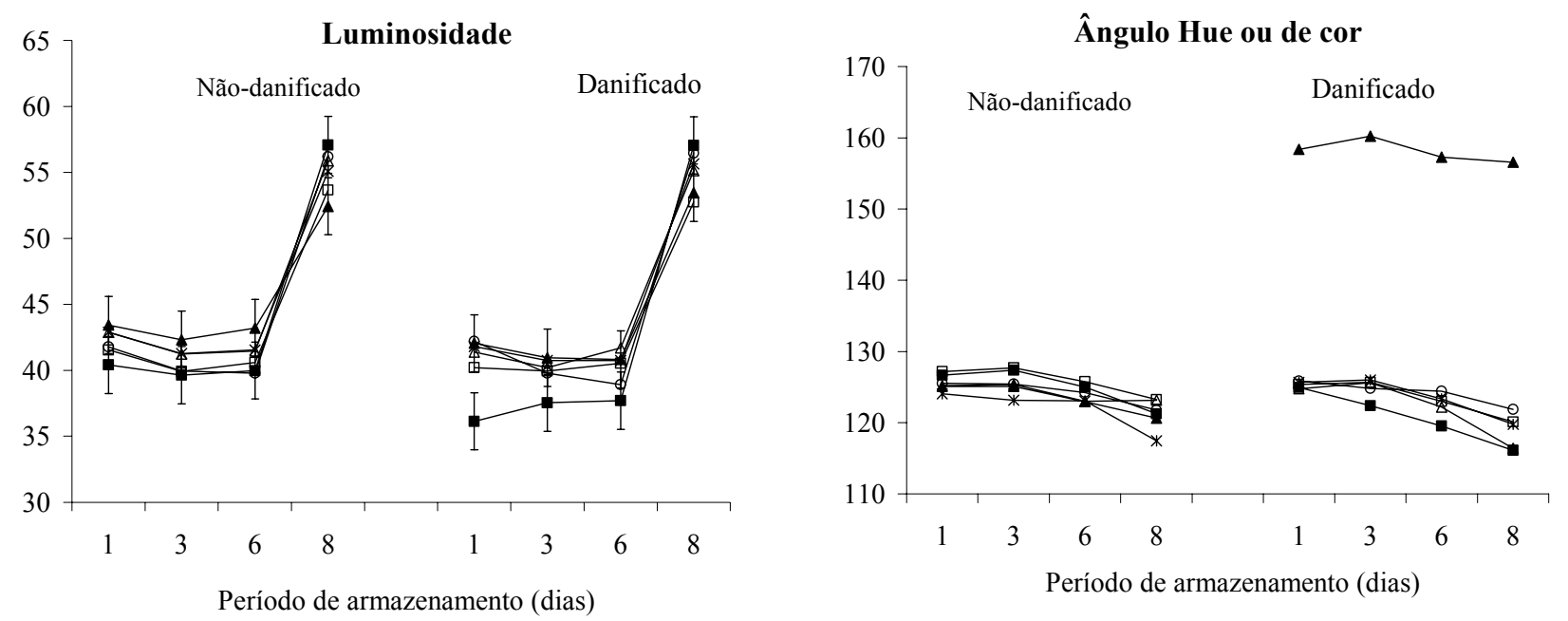

Cromaticidade

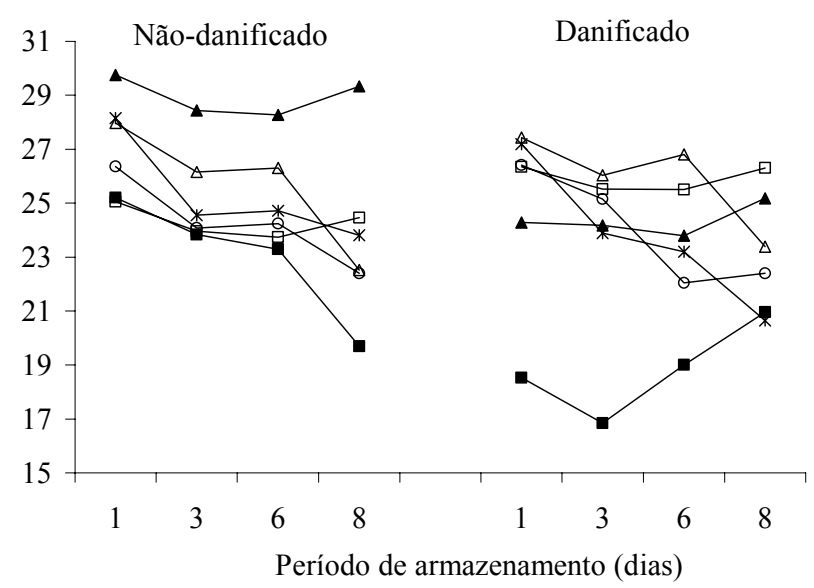

$\begin{array}{lll}\rightarrow \text { Testemunha } & \star \text { Impacto }(2,0 \mathrm{~m}) & \triangle \text { Impacto }(1,5 \mathrm{~m}) \\ - \text { Compressão }(12 \mathrm{~kg} / 6 \mathrm{~h}) & \square \text { Compressão }(6 \mathrm{~kg} / 12 \mathrm{~h}) & * \text { Corte }\end{array}$

FIGURA 3. Luminosidade, ângulo Hue ou de cor e cromaticidade da casca de abacates 'Geada', submetidos ou não a diferentes danos mecânicos e armazenados sob condições de ambiente $\left(25 \pm 1{ }^{\circ} \mathrm{C}\right.$ e $64 \pm 6 \%$ UR). Para a luminosidade: DMS = diferença mínima significativa $(p \leq 0,05)$. Lightness, Hue or color angle and chromaticity of 'Geada' avocados skin, submitted or not at different mechanical damages and stored at room conditions $\left(25 \pm 1^{\circ} \mathrm{C}\right.$ and $64 \pm 6 \%$ RH). To lightness: LSD = least significant difference $(\mathrm{p} \leq \mathbf{0 . 0 5})$.

Os danos não afetaram a evolução nos teores de sólidos solúveis e de acidez titulável da polpa dos frutos durante o período de armazenamento (Figura 4). Observa-se que esses valores apresentaram tendência à diminuição com o passar do tempo, o que foi atribuído ao amadurecimento dos frutos, com exceção do tratamento de cortes.

A evolução da perda da massa fresca dos frutos, representada pelas equações da Tabela 1, indica que há relação significativa e inversa entre a perda de massa e o tempo de armazenamento. 

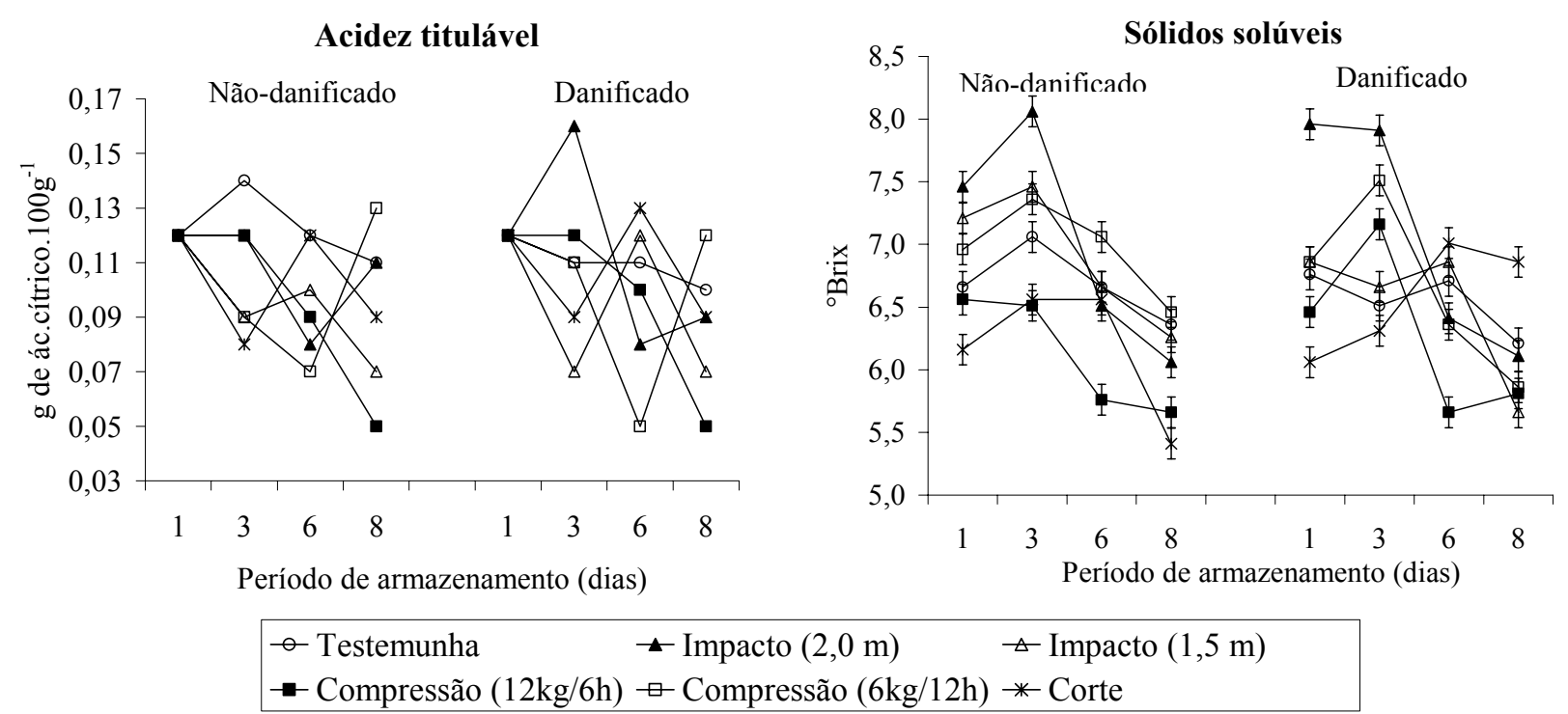

FIGURA 4. Acidez titulável ( $\mathrm{g}$ de ácido cítrico $100 \mathrm{~g}^{-1}$ ) e sólidos solúveis ( ${ }^{\circ}$ Brix) em abacates 'Geada', submetidos ou não a diferentes danos mecânicos e armazenados sob condições de ambiente $\left(25 \pm 1{ }^{\circ} \mathrm{C}\right.$ e $64 \pm 6 \%$ UR). Para teores de sólidos solúveis: $\mathrm{DMS}=$ diferença mínima significativa $(\mathrm{p} \leq 0,05)$. Titratable acidity (g citric acid $100 \mathrm{~g}^{-1}$ ) and soluble solids ( $\left.{ }^{\circ} \mathrm{Brix}\right)$ of 'Geada' avocados, submitted or not at different mechanical damages and stored at room conditions $\left(25 \pm 1^{\circ} \mathrm{C}\right.$ and $64 \pm 6 \% \mathrm{RH})$. To soluble solids: LSD = least significant difference $(p \leq 0.05)$.

TABELA 1. Equações de regressão obtidas para a evolução da perda da massa fresca de abacates 'Geada', submetidos ou não a diferentes danos mecânicos e armazenados sob condições de ambiente $\left(25 \pm 1{ }^{\circ} \mathrm{C}\right.$ e $64 \pm 6 \%$ UR). Regression equations to weight loss evolution of 'Geada' avocados, submitted or not at different mechanical damages and stored at room conditions $\left(25 \pm 1^{\circ} \mathrm{C}\right.$ and $\left.64 \pm 6 \% \mathrm{RH}\right)$.

\begin{tabular}{lcc}
\hline Tratamentos & $\mathrm{Y}=\mathrm{A}+\mathrm{BX}$ & $\mathrm{R}^{2}$ \\
\hline Testemunha & $\mathrm{Y}=104,8750-5,2940 \mathrm{X}$ & $0,9950^{* *}$ \\
Compressão $(6 \mathrm{~kg} / 12 \mathrm{~h})$ & $\mathrm{Y}=104,5300-5,0070 \mathrm{X}$ & $0,9934^{* *}$ \\
Compressão $(12 \mathrm{~kg} / 6 \mathrm{~h})$ & $\mathrm{Y}=105,4750-5,8360 \mathrm{X}$ & $0,9958^{* *}$ \\
Impacto $(1,5 \mathrm{~m})$ & $\mathrm{Y}=105,1650-5,7220 \mathrm{X}$ & $0,9928^{* *}$ \\
Impacto $(2,0 \mathrm{~m})$ & $\mathrm{Y}=105,4800-6,0610 \mathrm{X}$ & $0,9937^{* *}$ \\
Corte & $\mathrm{Y}=105,2700-5,7850 \mathrm{X}$ & $0,9938^{* *}$ \\
\hline
\end{tabular}

$\mathrm{Y}=$ massa do fruto $(\mathrm{g})$ e $\mathrm{X}=$ dias de armazenamento

$(* *)$ - significativo a $1 \%$ de probabilidade

Comparando-se essas equações quanto ao paralelismo das retas que representam, verificou-se que elas não se mostraram significativamente diferentes, indicando que os danos não tiveram efeito sobre a taxa da perda de massa durante o período de armazenamento.

De maneira geral, danos mecânicos em abacate 'Geada' não afetaram os parâmetros avaliados, que evoluíram gradativamente e em função do amadurecimento, ao longo do período de armazenamento. Esse resultado levou à realização da etapa seguinte, na qual o período de tempo de exposição dos frutos ao peso, no tratamento compressão, foi aumentado.

\section{Etapa 2}

Assim como na Etapa 1, nos abacates 'Geada' que receberam os cortes, as marcas puderam ser observadas desde o primeiro dia, as quais evoluíram de leves sinais para cicatrizes, conforme visualizado na Figura 6. 
Os abacates que receberam impacto após queda de 2,0 $\mathrm{m}$ de altura também apresentaram fissuras na polpa, ao redor do caroço, no terceiro dia. À medida que eles foram amadurecendo, essas fissuras foram sendo preenchidas por material originado do caroço, conforme indicado na Figura 5. As frutas não apresentavam sintomas externos visíveis (Figura 6).

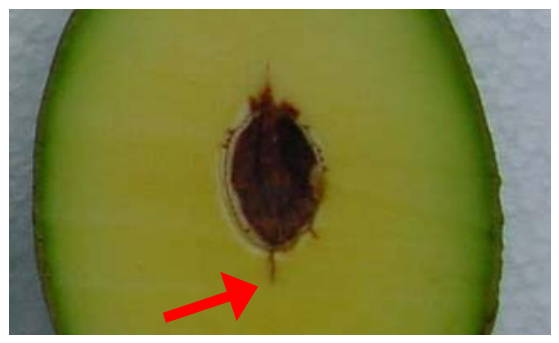

FIGURA 5. Fissura interna em abacate 'Geada' submetido ao impacto, após seis dias de armazenamento sob condições de ambiente $\left(25 \pm 1{ }^{\circ} \mathrm{C}\right.$ e $62 \pm 6 \%$ UR). Internal fissure of 'Geada' avocados submitted to impact, after storage for 6 days at room conditions $\left(25 \pm 1^{\circ} \mathrm{C}\right.$ and $\left.62 \pm 6 \% \mathrm{RH}\right)$.

No tratamento compressão, em que se aplicaram $12 \mathrm{~kg}$ por $24 \mathrm{~h}$, a casca dos frutos, no local de contato com o peso, apresentou coloração verde mais escura; no terceiro dia de armazenamento, já não apresentava sintoma externo visível. Observou-se que, mesmo aumentando o tempo de exposição ao peso, a polpa dos abacates não foi marcada por esse dano, como pode ser visualizado na Figura 6.
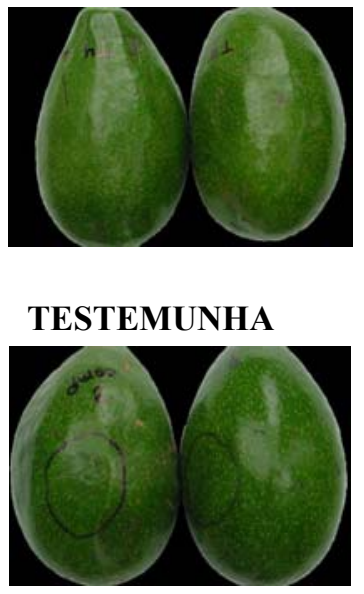

COMPRESSÃO
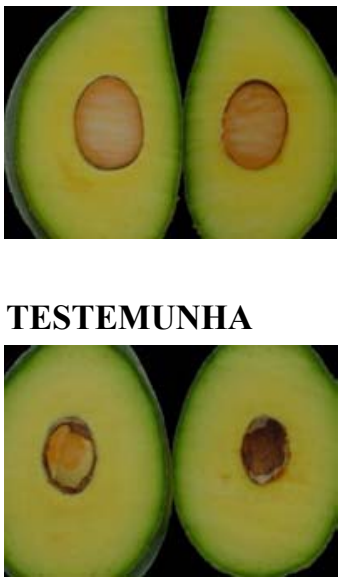

COMPRESSÃO
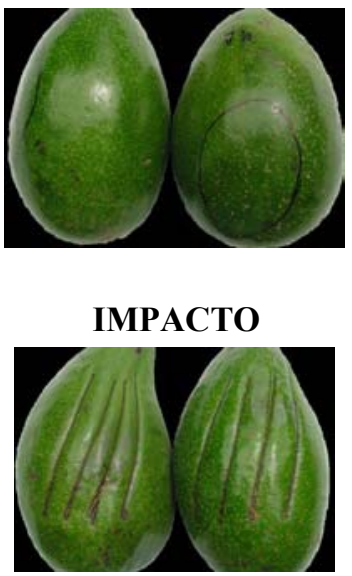

CORTE

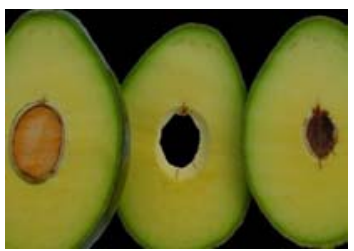

IMPACTO

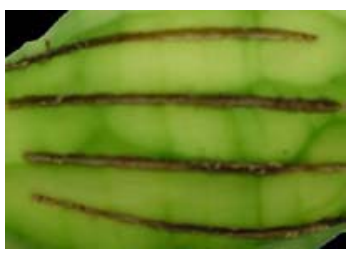

CORTE

FIGURA 6. Aparência interna e externa de abacates 'Geada' submetidos a diferentes tratamentos, após 6 dias de armazenamento, sob condições de ambiente $\left(25 \pm 1{ }^{\circ} \mathrm{C}\right.$ e $62 \pm 6 \%$ UR). Internal and external appearance of 'Geada' avocados submitted at different treatments, after storage for 6 days at room conditions $\left(25 \pm 1^{\circ} \mathrm{C}\right.$ and $62 \pm 6 \%$ RH).

Comparando-se a evolução da luminosidade da casca nas áreas danificadas com as nãodanificadas, ao longo do período de armazenamento (Figura 7), observa-se que as danificadas pela compressão apresentavam-se mais escurecidas no início do armazenamento, que se reduziu com o tempo, e, após oito dias de armazenamento, não aparentavam sinais de dano. O dano por impacto apresentou queda desse parâmetro no oitavo dia de armazenamento. KASAT et al. (2007) verificaram que pêssegos 'Aurora-1' submetidos ao impacto e à compressão tornaram-se mais escurecidos, enquanto, em goiabas das cultivares Paluma e Pedro Sato, a área danificada apresentou-se mais escura nos frutos submetidos ao impacto, compressão e corte (MATTIUZ \& DURIGAN, 2001a). SAMIM \& BANKS (1993) também observaram que as áreas danificadas de maçãs ‘Granny Smith' se tornaram mais escuras que as regiões-controle. 
Na Figura 7, também são mostrados os valores do ângulo Hue ou de cor da casca dos abacates 'Geada', durante o período de armazenamento, permitindo observar que esses valores se mantiveram praticamente estáveis até o oitavo dia, com exceção das áreas danificadas pelo impacto, que, no oitavo dia de armazenamento, se apresentavam mais verdes do que nos frutos submetidos aos demais tratamentos, o que também foi observado na Etapa 1. DURIGAN et al. (2005) observaram que dano por impacto levou à maior perda na cor verde em limas ácidas 'Tahiti', principalmente na região danificada, enquanto KASAT et al. (2007) verificaram que pêssegos submetidos ao impacto retiveram a cor amarelo-esverdeada, indicando retardo no amadurecimento. Em goiabas, MATTIUZ \& DURIGAN (2001a) também constataram que as mudanças no ângulo de cor foram mais rápidas nos frutos que sofreram danos mecânicos. Segundo esses autores, os danos levaram à alteração no processo metabólico dessas regiões e, como conseqüência, à irregularidade no amadurecimento.
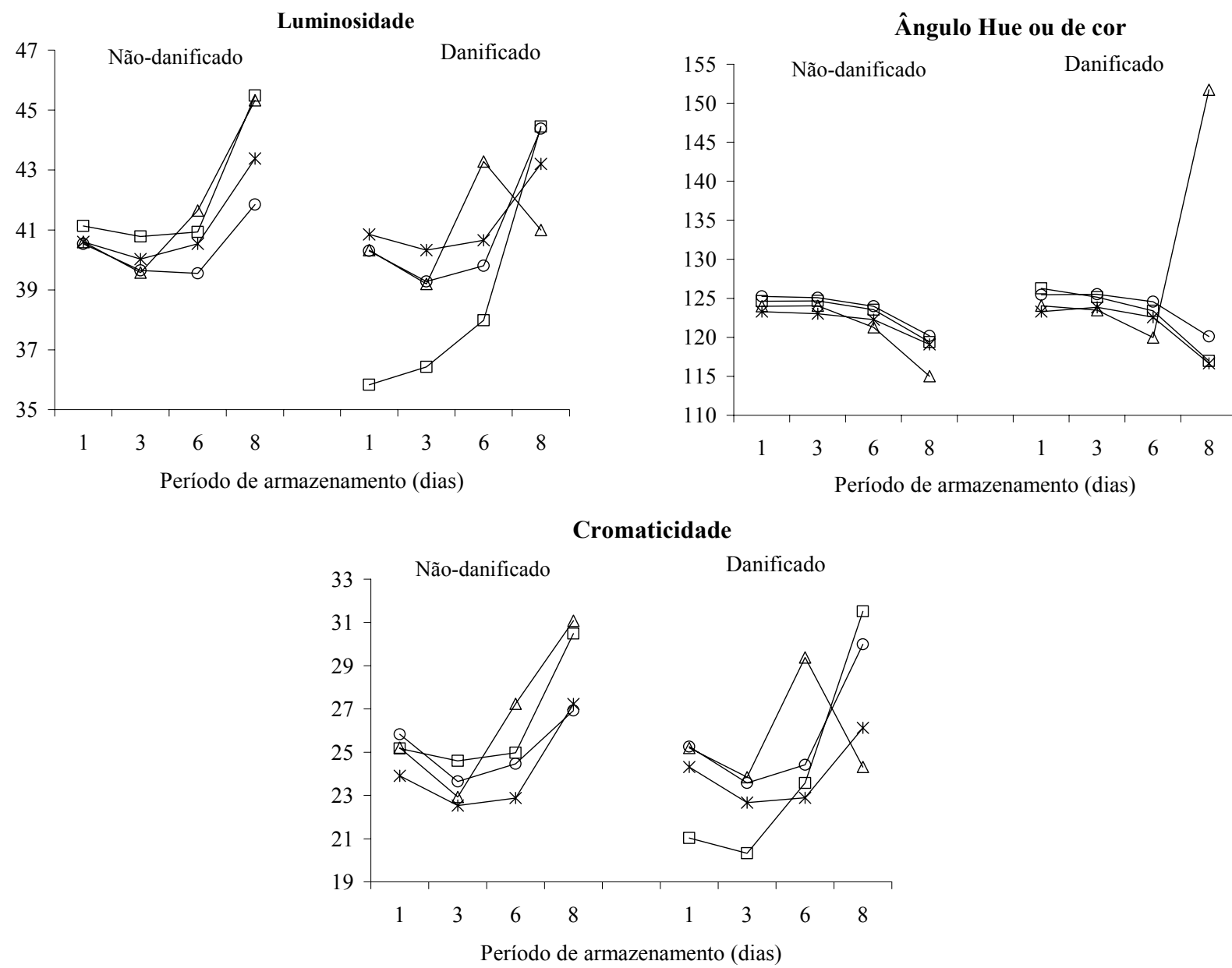

$๑$ Testemunha $\triangle$ Impacto $\square$ Compressão $*$ Corte

FIGURA 7. Luminosidade, ângulo Hue ou de cor e cromaticidade da casca de abacates 'Geada', submetidos ou não a diferentes danos mecânicos, armazenados sob condições de ambiente $\left(25 \pm 1{ }^{\circ} \mathrm{C}\right.$ e $62 \pm 6 \%$ UR). Lightness, Hue or color angle and chromaticity of 'Geada' avocados skin, submitted or not at different mechanical damages and stored at room conditions $\left(25 \pm 1^{\circ} \mathrm{C}\right.$ and $\left.62 \pm 6 \% \mathrm{RH}\right)$. To lightness: $\mathbf{L S D}=$ least significant difference $(\mathrm{p} \leq \mathbf{0 . 0 5})$.

A cromaticidade das partes danificadas, em todos os tratamentos e ao longo do período de armazenamento, encontra-se na Figura 7. No terceiro dia de armazenamento, em todos os tratamentos, houve pequena diminuição desse parâmetro para depois aumentar até o último dia, com exceção do impacto, que, no oitavo dia, houve redução desse parâmetro. $O$ aumento da luminosidade, conjugado com o aumento da cromaticidade, revela que, nos frutos, a coloração 
tornou-se menos verde e pode ser atribuído à redução nos teores de clorofila desse material. Nas áreas danificadas, de maneira geral, esses valores são sempre inferiores ao controle, com exceção feita ao impacto, no qual, provavelmente, houve menor degradação da clorofila no local injuriado.

A acidez titulável, de maneira geral, diminuiu durante o período de armazenamento nos frutos submetidos aos diferentes danos (Figura 8). Pode-se observar, também, que, na primeira etapa, a acidez da polpa apresentou-se com maiores valores que na segunda; isso pode ser devido ao estádio de desenvolvimento dos frutos ou à época de crescimento dos mesmos, uma vez que eles foram colhidos em épocas diferentes, ou seja, na primeira etapa foram colhidos no início da safra e, no segundo experimento, no meio da safra.

Observa-se ainda, na Figura 8, que as partes danificadas e as não-danificadas apresentaram o mesmo comportamento, o que difere de outros autores, que encontraram menor conteúdo de acidez em tomates, goiabas, mangas e pêssegos submetidos a diferentes danos mecânicos (MORETTI, 1998; MATTIUZ \& DURIGAN, 2001b; DURIGAN et al., 2005; KASAT et al., 2007).

Os danos não afetaram a tendência de redução dos teores de sólidos solúveis na polpa dos frutos durante o período de armazenamento (Figura 8), indicando o uso desses sólidos como fonte de energia. Observa-se que esses valores foram maiores que na Etapa 1, reafirmando o efeito da época de colheita. $\mathrm{O}$ amadurecimento em abacates está diretamente relacionado, entre outros fatores, ao aumento no conteúdo de óleo, cuja produção consome carboidratos, principalmente os solúveis (BERTLING et al., 2003).
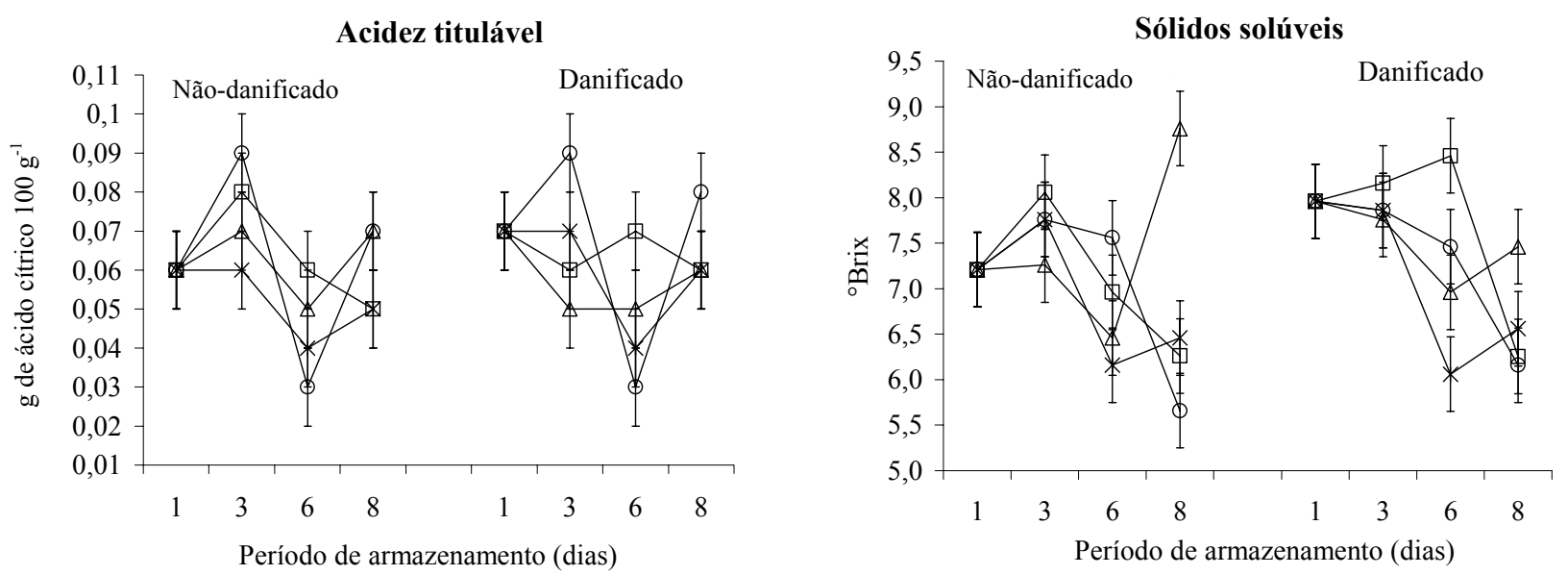

$\multimap$ Testemunha $\triangle$ Impacto $\square$ Compressão * Corte

FIGURA 8. Acidez titulável (g de ácido cítrico $100 \mathrm{~g}^{-1}$ ) e sólidos solúveis ( ${ }^{\circ}$ Brix) em abacates 'Geada', submetidos ou não a diferentes danos mecânicos, armazenados sob condições de ambiente $\left(25 \pm 1{ }^{\circ} \mathrm{C}\right.$ e $\left.62 \pm 6 \% \mathrm{UR}\right)$. DMS = diferença mínima significativa $(\mathrm{p} \leq 0,05)$. Titratable acidity (g citric acid $\left.100 \mathrm{~g}^{-1}\right)$ and soluble solids ( ${ }^{\circ}$ Brix) of 'Geada' avocados, submitted or not at different mechanical damages and stored at room conditions $\left(25 \pm 1^{\circ} \mathrm{C}\right.$ and $\left.62 \pm 6 \% \mathrm{RH}\right)$. LSD $=$ least significant difference $(p \leq 0.05)$.

A evolução da perda de massa fresca nos frutos submetidos aos diferentes tratamentos pode ser representada pelas equações mostradas na Tabela 2, indicando que há relação significativa e indireta entre sua evolução e o tempo de armazenamento.

Comparando-se essas equações quanto ao paralelismo, verificou-se que somente o tratamento compressão diferiu significativamente, a $5 \%$ de probabilidade, da testemunha $(2,94 *)$ e do corte $\left(2,99^{*}\right)$. Isso indica que o dano causado pela compressão levou à menor intensidade de perda de massa, devido à transpiração. KASAT et al. (2007) observaram que o impacto proporcionou a maior perda de massa fresca em pêssegos 'Aurora-1', enquanto, em lima ácida 'Tahiti', os cortes foram os mais prejudiciais quanto a esse atributo (DURIGAN et al., 2005). 
TABELA 2. Equações de regressão obtidas para a evolução da perda da massa fresca de abacates 'Geada', submetidos ou não a diferentes lesões, armazenados sob condições de ambiente $\left(25 \pm 1{ }^{\circ} \mathrm{C}\right.$ e $62 \pm 6 \%$ UR). Regression equations to weight loss evolution of 'Geada' avocados, submitted or not at different mechanical damages and stored at room conditions $\left(25 \pm 1^{\circ} \mathrm{C}\right.$ and $\left.62 \pm 6 \% \mathrm{RH}\right)$.

\begin{tabular}{lcc}
\hline Tratamentos & $\mathrm{Y}=\mathrm{A}+\mathrm{BX}$ & $\mathrm{R}^{2}$ \\
\hline Testemunha & $\mathrm{Y}=101,5936-2,1891 \mathrm{X}$ & $0,9960^{* *}$ \\
Compressão & $\mathrm{Y}=101,9800-1,7450 \mathrm{X}$ & $0,9988^{* *}$ \\
Corte & $\mathrm{Y}=101,3903-2,6140 \mathrm{X}$ & $0,9884^{*}$ \\
Impacto & $\mathrm{Y}=101,4771-2,2588 \mathrm{X}$ & $0,9938^{* *}$ \\
\hline
\end{tabular}

$\mathrm{Y}=$ massa do fruto $(\mathrm{g}) \mathrm{e} \mathrm{X}=$ dias de armazenamento

$(* *)$ - significativo a $1 \%$ de probabilidade; $(*)$ - significativo a $5 \%$ de probabilidade.

\section{CONCLUSÕES}

O dano mecânico por corte apresentou excelente cicatrização, sem afetar a polpa nas vizinhanças desses danos. Os abacates 'Geada' não se mostraram suscetíveis a danos mecânicos por compressão quando aplicados $6 \mathrm{~kg}$ de peso por 12 horas e $12 \mathrm{~kg}$ por 6 horas seguidas, e quando aumentou o período de exposição $(12 \mathrm{~kg} / 24 \mathrm{~h})$ fez com que a casca dos frutos, no local de contato com o peso, apresentasse coloração verde mais escura até o terceiro dia de armazenamento. Nas cultivares de abacates com frutos grandes, como o 'Geada', queda de alturas maiores que $2 \mathrm{~m}$ levou os frutos a rachaduras. Até os dois metros, formaram-se fissuras ao redor do caroço, que foram preenchidas por filamentos de aspecto duro, do próprio caroço, e a polpa não se mostrou amolecida ou deteriorada nesse local, sendo esse dano não-visível externamente.

\section{AGRADECIMENTOS}

À UNESP/FCAV e à FAPESP (Proc. $n^{\circ}$ 02/08828-3).

\section{REFERÊNCIAS}

AOAC. Official methods of analysis of the Association of Official Analytical Chemists International. $16^{\text {th }}$ ed. Washington: Ed. Patricia Cummiff, 1997.v.2, cap. 37. método $942.15 \mathrm{e}$ método 932.12 .

BERTLING, I.; BOWER, J. P.; DENNISON, M. T. ¿Está el contenido en azúcares de los cultivares de aguacate relacionado con las características de calidad de su fruta?. In: WORLD AVOCADO CONGRESS, 5., 2003, Granada-Málaga. Proceedings... Granada-Málaga: Consejería de Agricultura y Pesca, 2003. p.88.

BLEINROTH, E.W. Colheita e tratamentos. In: GAYET, J.P., BLEINROTH, E.W., MATALLO, M., GARCIA, E.E.C., GARCIA, A.E., ARDITO, E.F.G., BORDIN, M.R. (Ed.). Abacate para exportação: procedimentos de colheita e pós-colheita. Brasília: Embrapa-SPI, 1995. p.10-23. (Série publicações técnicas FRUPEX, 15).

BLEINROTH, E.W.; CASTRO, J.V. de. Matéria-prima. In: ITAL. Abacate: cultura, matéria-prima, processamento e aspectos econômicos. 2.ed. Campinas: ITAL, 1992. p.58-148.

CAMARGO, G.F.; MANCO, J.R. Participação do mercado de abacate no ETSP da CEAGESP em 2002. Net, Jaboticabal, jul. 2004. Seção Informações econômicas sobre abacate. Disponível em: http://todafruta.com.br. Acesso em: 10 jul. 2007.

DONADIO, L.C. Abacate para exportação: aspectos técnicos de produção. Brasília: DENACOOP, 1995.109 p. (Série publicações técnicas, DENACOOP/FRUPEX, 2). 
DURIGAN, M.F.B.; MATTIUZ, B.H.; DURIGAN, J.F. Injúrias mecânicas na qualidade póscolheita de lima ácida 'Tahiti' armazenadas sob condição ambiente. Revista Brasileira de Fruticultura, Jaboticabal, v.27, n.3, p.369-72, 2005.

FRANCISCO, V.L.F. dos S.; BAPTISTELLA, C. da S.L. Cultura do abacate no Estado de São Paulo. Informações Econômicas, São Paulo, v.35, n.5, p.27-41, 2005.

GAYET, J.P.Características das frutas de exportação. In: GAYET, J.P., BLEINROTH, E.W., MATALLO, M., GARCIA, E.E.C., GARCIA, A.E., ARDITO, E.F.G., BORDIN, M.R. (Ed.). Abacate para exportação: procedimentos de colheita e pós-colheita. Brasília: Embrapa-SPI, 1995. p.9 (Série publicações técnicas FRUPEX, 15).

KASAT, G.F.; MATTIUZ, B.H.; OGASSAVARA, F.O.; BIANCO, M.S.; MORGADO, C.M.A.; CUNHA JÚNIOR, L.C. Injúrias mecânicas e seus efeitos em pêssegos 'Aurora-1'. Revista Brasileira de Fruticultura, Jaboticabal, v.29, n.2, p.318-22, 2007.

MATTIUZ, B.H. Injúrias mecânicas e processamento mínimo de goiabas: fisiologia e qualidade pós-colheita. 2002. 120 f. Tese (Doutorado em Produção Vegetal) - Faculdade de Ciências Agrárias e Veterinárias, Universidade Estadual Paulista, Jaboticabal, 2002.

MATTIUZ, B,H; DURIGAN, J.F. Efeito de injúrias mecânicas na firmeza e coloração de goiabas das cultivares Paluma e Pedro Sato. Revista Brasileira de Fruticultura, Jaboticabal, v.23, n.2, p.277-81, 2001a.

MATTIUZ, B.H.; DURIGAN, J.F. Efeito de injúrias mecânicas no processo respiratório o nos parâmetros químicos em goiabas 'Paluma' e 'Pedro Sato'. Revista Brasileira de Fruticultura, Jaboticabal, v.23, n.2, p.282-7, 2001 b.

MOHSENIN, N.N. Physical properties of plant and animal materials: structure, physical characteristics and mechanical properties. $2^{\text {nd }}$ ed. New York: Gordon and Breach, 1986. 891 p.

MORETTI, C.L. Injúrias internas de impacto em frutos de tomate: fisiologia e conservação póscolheita. 1998. 132 f. Tese (Doutorado em Produção Vegetal) - Universidade Federal de Viçosa, Viçosa, 1998.

NETER, J; WASSERMAN, W.; WHITMORE, G. A. Applied linear statistical models. Massachussetts: Allyn and Bacon, 1978. 745 p.

QUINTANA, M.E.G.; PAULL, R.E. Mechanical injury during postharvest handling of 'Solo' papaya fruit. Journal of the American Society for Horticultural Science, Alexandria, v.118, n.5, p.618-22, 1993.

SAMIM, W.; BANKS, N.H. Colour changes in bruised apple fruit tissue. New Zealand Journal of Crop and Horticultural Science, Wellington, v.21, n.4, p.367-72, 1993.

WILEY, R.C. Frutas y hortalizas mínimamente procesadas y refrigeradas. Zaragoza: Editorial Acribia, 1997. 363 p.

WOOLF, A.B.; MACRAE, E.A.; SPOONER, K.J.; REDGWELL, R.J. Changes to physical properties of the cell wall and polyuronides in response to heat treatment of 'Fuyu' persimmon that alleviate chilling injury. Journal of American Society for Horticultural Science, Alexandria, v.122, n.5, p.698-702, 1997. 